\title{
CORALLINE (G)REEF
}

\section{Pam McKinlay with Anna Kluibenschedl}

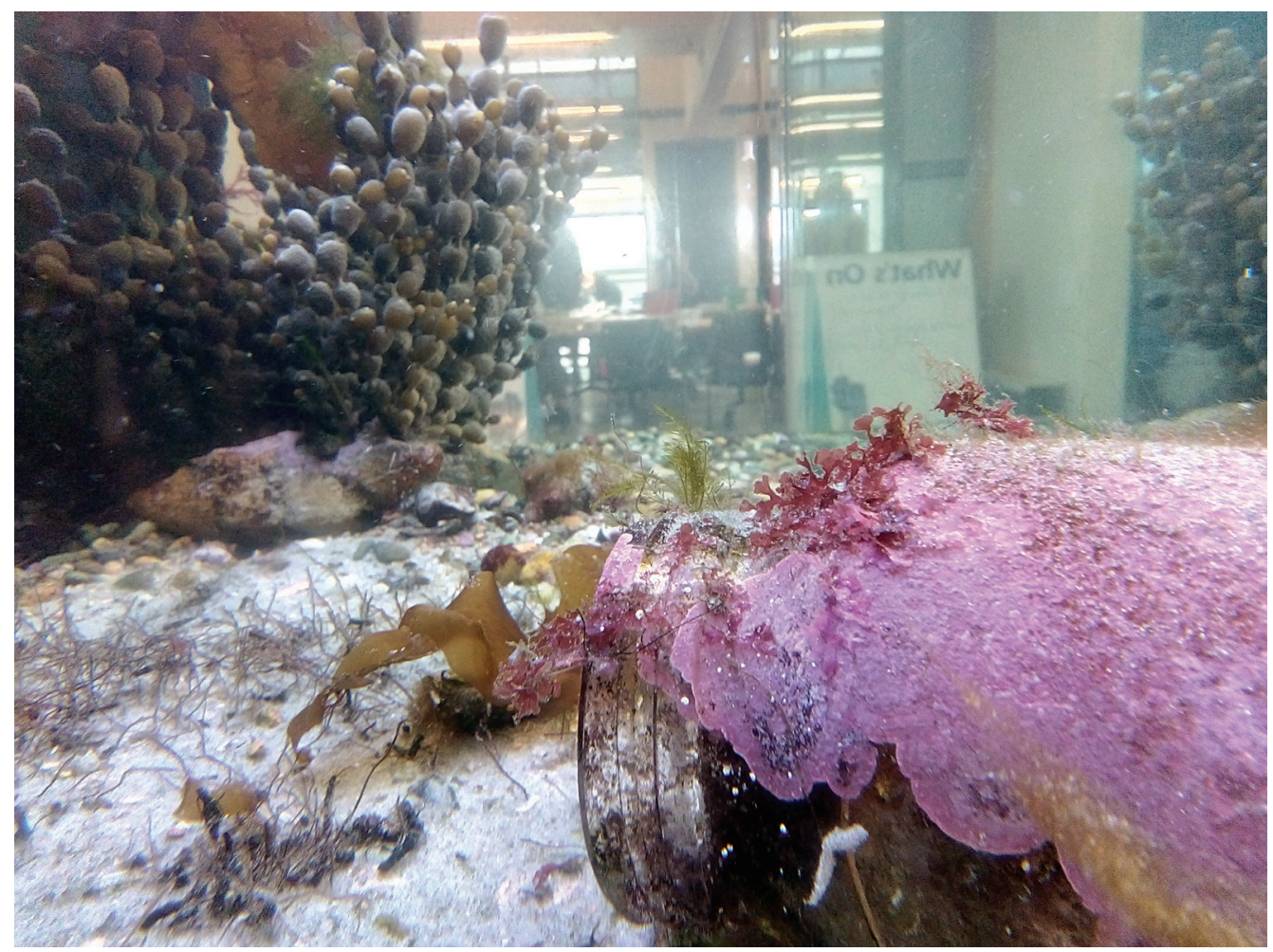

Figure I. A glass jar in the entrance tank at the Portobello Aquarium, Dunedin.

Rocks, glass and slow-moving molluscs. Such objects in the Portobello Aquarium tanks are all commonly cloaked in a vibrant pink covering, which I discovered last year was coralline algae. Coralline algae is the intermediary between rock and life. In the sea, coralline algae form a cloak over the rocks and other substrate such as slow-growing paua, or detritus in the ocean such as glass and other introduced objects (as in Figure 1). The connection between rock and (marine) life is recognised in whakatauki and whakapapa in Te Ao Māori. In Māori lore, shellfish and all forms of seaweed are said to cling to their foster parents, Rakahore and Tuamata, rock and stones, in order to provide shelter for the other offspring of Hinemoana (the ocean), which are listed as the many shellfish.'

In conversation with Anna Kluibenschedl, one of the scientists taking part in the Art + Science Project - Oceans $2018,{ }^{2}$ I learned about the importance of coralline algae in the ocean. 

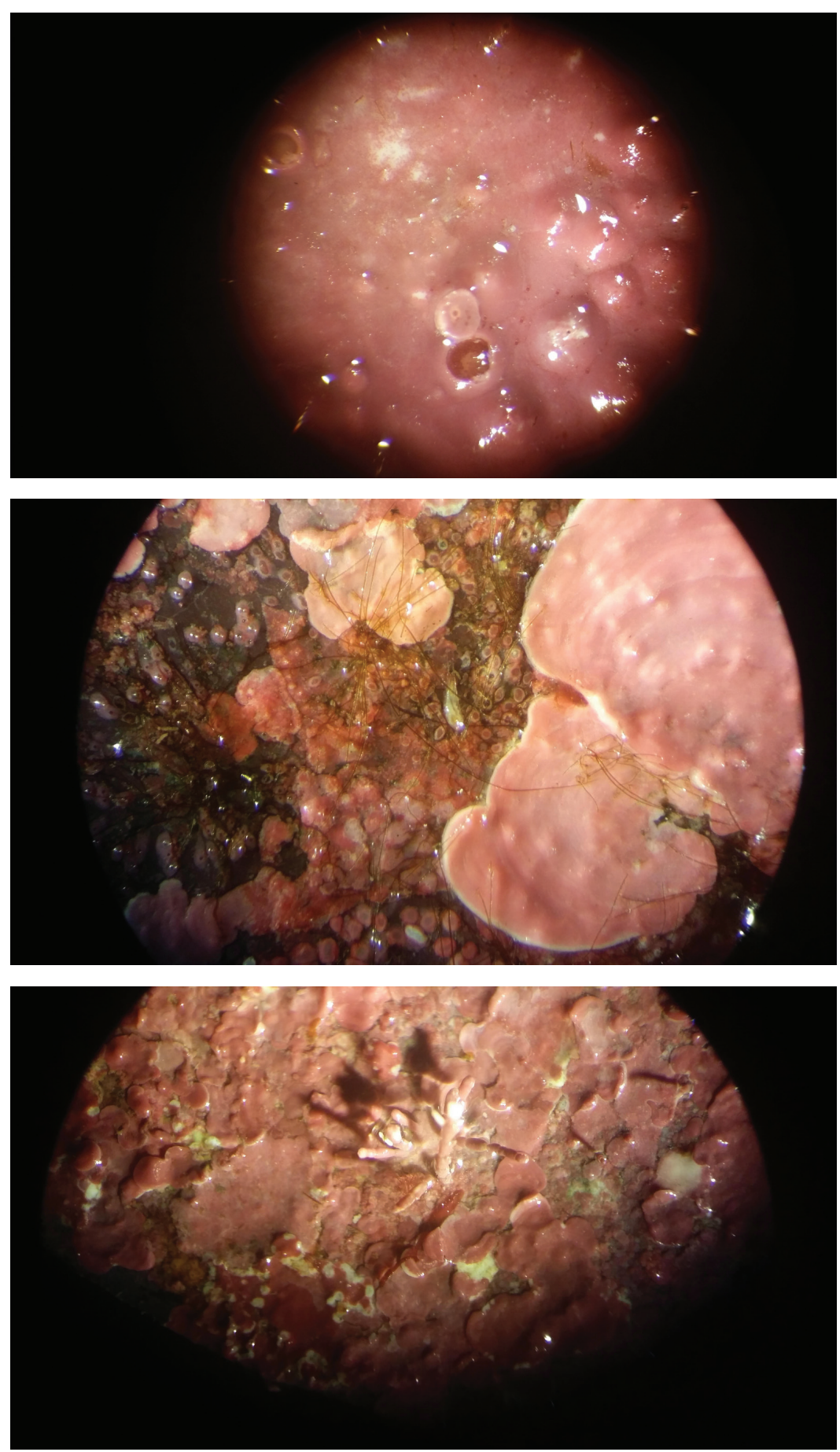

Figure 2. Composite image of Anna Kluibenschedl 's microscope images of coralline algae. 
New Zealand has some amazing algae. Most algae are somewhat soft or at least leathery, but coralline algae are different. They are hard and have a carbonate skeleton like snails or mussels.

All coralline algae are pink and form either crusts or tufts that grow on rocks. The pink colour comes from a pigment they use for photosynthesis, ${ }^{3}$ which means that they need light to produce energy. Coralline algae are divided into two groups. The ones that form tufts are called geniculate-type, which means jointed. They have carbonate-free joints, making them flexible so they can sway with the water movement. The crust-forming ones are called crustose and they can resist the water motion by clinging to the rocks. Sometimes they are also called the glue of the reef, as they hold the reef together.

Coralline algae are found in every ocean from the poles to the tropics. They grow quite slowly, but form stable structures that can protect coral reefs from the impact of waves. The deepest algae, found at $270 \mathrm{~m}$, is a crustose form. ${ }^{4}$ It is extraordinary that they can exist so deep, because at this depth there is almost no light left for them to photosynthesise.

Many animals in the sea start their life as swimming larvae, drifting through the ocean. When it is time for them to find a place to settle down, many of them will attach and never move again, such as barnacles and sponges. Crustose coralline algae give off chemical signals that help guide some larvae, such as paua and sea urchin larvae, to suitable habitat. These larvae have a much higher success and survival rate when they settle on coralline algae. ${ }^{5}$

From many experiments, it is clear that the changes that are happening as a result of ocean warming and ocean acidification (OA) are producing problems for coralline algae. In future, they might have a much harder time forming their carbonate skeletons. While these species are not doing so well, other algae might be doing much better and outgrow them. Being weaker and growing even more slowly, coralline algae might not be able to provide the same services as they used to.

\section{Anna Kluibenschedl}

Many of the climate effects we are observing today were caused by actions carried out three to five decades ago. We are becoming increasingly familiar with the results of the burning of fossil fuels in the loading of the atmosphere with excess carbon emissions; the increased frequency and severity of extreme weather, and rising sea levels. But there are other effects caused by carbon dioxide dissolving in the ocean. This causes an increase in the acidity of the sea, which in turn affects ocean bicarbonate chemistry in a process called ocean acidification. Ocean acidification, often called the "evil twin" of climate change, affects the availability of carbonate ions, essential for the formation of hardened structures such as corals and shells.

The Coralline (G)Reef tapestry started as an idea for a participatory weaving project in the exhibition "Ōku Moana" (My Oceans) at the International New Zealand Science Festival, $2018 .{ }^{6}$ Weaving is a metaphor for life. One of the joys of taking part in community weaving projects is that when people are weaving alongside each other, there is always talking, helping and sharing. It's a great time for story-telling for all ages. Each piece is unique to the time and place and community in which it was conceived, with the result being reflective of the creative process. The pieces we worked on in "Ōku Moana (My Oceans)" were dedicated to our understanding and celebration of the ocean. As we wove, we had the time to discuss the shapes and meaning of the artworks which were emerging. We were also able to emphasise the importance of coralline algae and other stories from our oceans, such as the impacts of plastic on fish populations, in two further weavings which arose from our conversations: Blue Planet III (a reference to Sir David Attenborough's Blue Planet series) and Tragic Plastic with an Armageddon Sunset (woven under the guiding hand of Vivien Dwyer).

Coralline (G)Reef is reminiscent of Anna's microscope research. The design is an interpretation of the growth rates and forms of CCA (crustose coralline algae) grown on an artificial substrate, a black disc, seen under magnification. In the foreground section, the composition follows the curve of one of the ambient discs. In the lab, the discs grown 


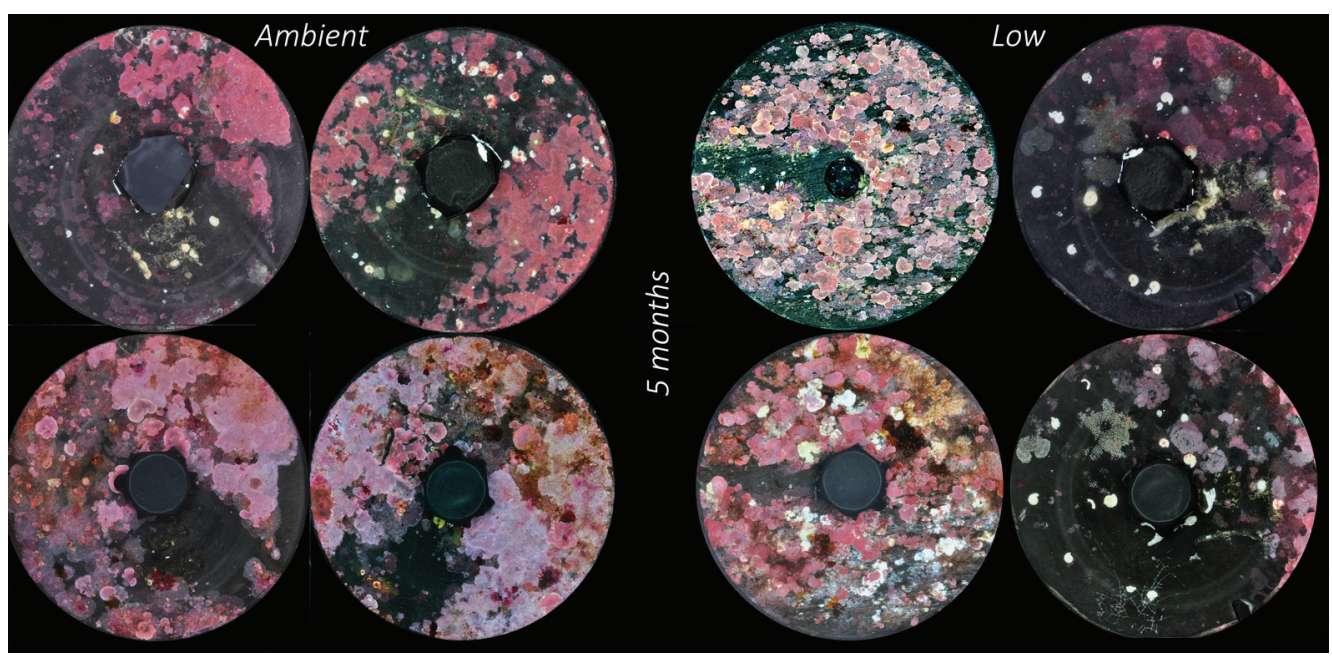

Figure 3. Anna Kluibenschedl's experimental discs for the growth of crustose coralline algae in ambient conditions and at elevated $\mathrm{CO} 2$.

under 'normal' ambient conditions thrive with pink life. The life cycle is represented here in the tapestry. With high population densities and greater coralline algae cover, there is competition in the surrounding environment, but the coralline algae are abundant in this "ambient" section.

The top part of the weaving is a response to the discs which were grown under simulated conditions of increased ocean acidification at future projected levels, which are predicted to occur if carbon emissions are not curbed in the next 50 years. Here the recruitment (offspring) of new algae seems impacted, with less coralline growth establishing. This part of the tapestry represents the encroaching effects of ocean acidification and adverse conditions where coralline algae are being outcompeted by other species of algae or simply not establishing at all, with reduced growth rates for those that are successful. The spacing of the warps and bulk of the mixed yarns created a third dimensionality in the woven algal growth areas. Extra texture was added through the introduction of feathery yarns and bulky browns, representing areas where non-crustose-type and non-pinkpigment-type algae were competing with CCA, and proving more successful.

The palette of pinks and other colours was derived from photographs of the lab discs used by Anna. The pinks were collected from various sources and were dyed and then assembled by rewinding several lengths of yarn into small balls for each alga. This created 'natural' variation among the tapestry algae. Very few of these balls of yarn were comprised of exactly the same combination of the mixed wools, reflecting the natural diversity and colour variation found on the wild ocean floor.

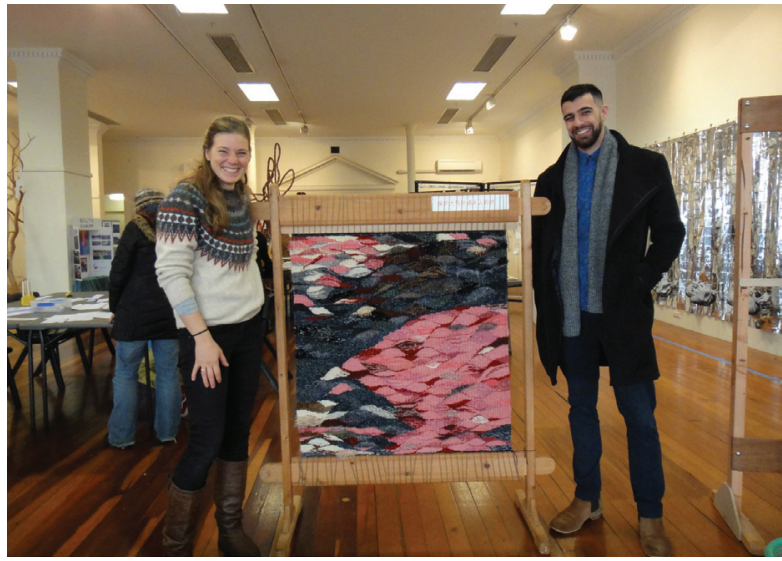

Figure 4. Anna Kluibenschedl and Dr Ro Allen in front of the weaving shown at the "Ōku Moana (My Oceans)" exhibition and community art-science workshops. 


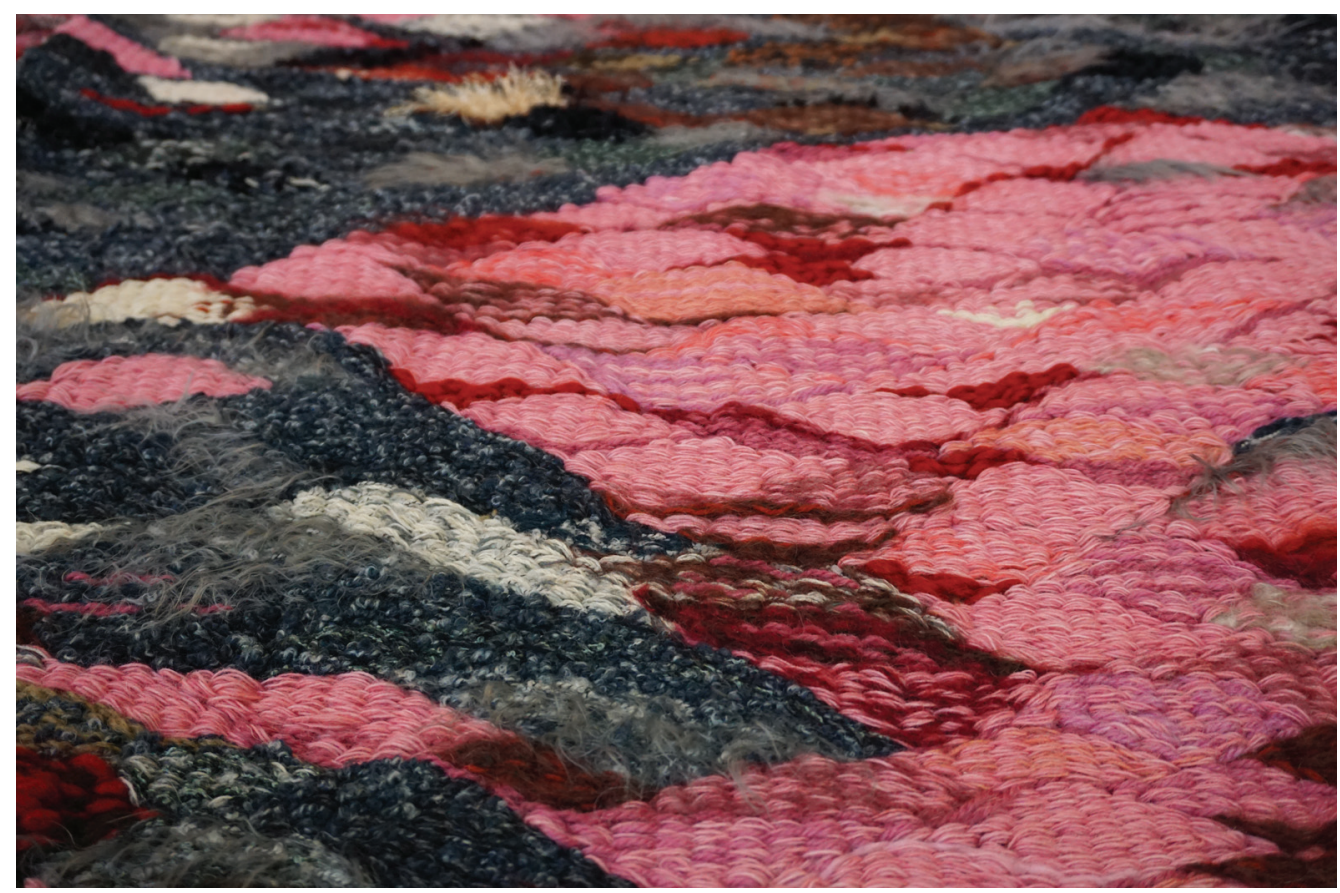

Figure 5. Completed weaving shown at "Ōku Moana (My Oceans) II," 20I9, displayed at Knox Church community halls; detail.

The final element in the tapestry involved the conscious use of wool to embed the idea that we need to move away from synthetic textiles, which shed microfibres into the waterways and oceans. Wool degrades in salt water, should it find itself there.

In summary, coralline algae are the colourful and strong stuff that holds our reefs together and provide a safe spot for seaweed and shellfish to settle. It is not only home and fortress, but the nursery of reef ecosystems and fisheries. Tapestry is a traditional way of conveying knowledge. Throughout history, textiles have used visual symbols and/or abstract design to portray both the known and the unknown or unseen. Projects such as this can bring a sensory awareness and reality to the impacts of climate change in the ocean by creating visual and tactile talking points and by offering new metaphors for thinking about the issues facing the marine world. In this case, the woven tapestry on its frame literally became a walking+talking post, appearing in unlikely public places such as the Octagon and in pop-ups by the peace pole in the Otago Museum Reserve. The project's colourful content and unusual context (a roving storyteller with a large rack loom as a prop) made for engaging conversation starters involving ocean acidification issues starting with the pink wonderland under the ocean, the existence of which many remain unaware.

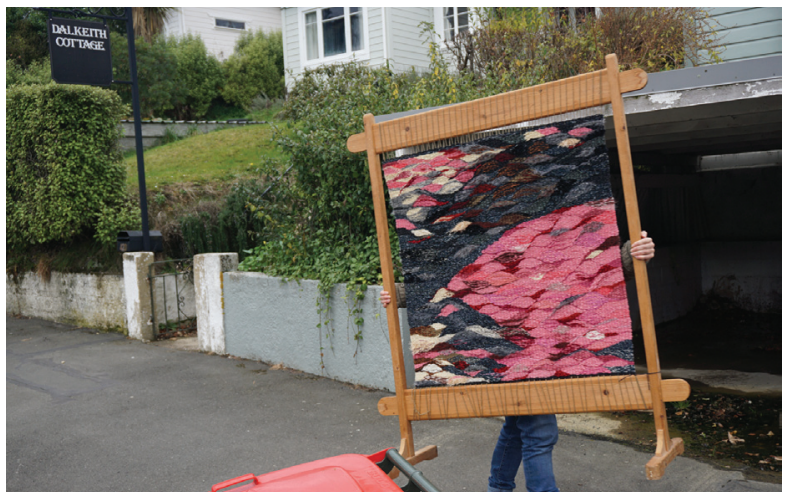

Figure 6. The walking loom. 
Pam McKinlay has a background in applied science and the history of art. She works predominantly in sculpture, weaving, ceramic and photography, in collaboration with other artists locally and nationally, in community outreach and education projects on the theme of climate change, sustainability and biodiversity. She works part-time in the Research and Postgraduate Office and Dunedin School of Art at Otago Polytechnic.

Anna Kluibenschedl is a PhD candidate in the Department of Marine Science at the University of Otago.

I Elsdon Best, Māori Religion and Mythology, Being An Account of the Cosmogony, Anthropogeny, Religious Beliefs and Rites, Magic and Folk Lore of the Māori Folk of New Zealand, Part 2, Dominion Museum Bulletin No. II (Wellington: PD Hasselberg, Government Printer, 1982) 253-6.

2 The Art + Oceans Project 2018 was the sixth in the ongoing 'Art + Science' Project series, where artists collaborate with scientists individually, or in pairs, to develop artworks for public exhibition relating to science interpreted in a broad context. For the exhibition catalogue, see https://issuu.com/dunedinschoolofart/docs/art_oceans_catalogue (accessed 5 September 2018).

3 WJ Woelkerling. "An Introduction," in Biology of the Red Algae, eds Kathleen M Cole and Robert G Sheath (Cambridge: Cambridge University Press, 1990), 517. The colour is the result of the photosynthetic pigment Phycoerythrin.

4 MM Littler, DS Littler, SM Blair and JN Norris. "Deepest Known Plant Life Discovered on an Uncharted Seamount," Science, 227:4682 (1985), 57-9. doi: I 0.I I 26/science.227.4682.57.

5 WA Nelson, "Calcified Macroalgae - Critical to Coastal Ecosystems and Vulnerable to Change: A Review," Marine and Freshwater Research, 60:8 (2009), 787-80 I. doi:I 0. I07I/MF08335.

6 The satellite exhibition "Ōku Moana (My Oceans)" was part of the International NZ Science Festival, July 20 I 8, held at the Community Gallery, Dunedin. http://www.scifest.org.nz/events/ku-moana (accessed 5 September 2018). 